\title{
Pembentukan Kader Kesehatan Reproduksi Remaja untuk Mengurangi Frekuensi Pernikahan Dini di Siswa SMP di Kecamatan Bangsalsari, Jember
}

\author{
${ }^{1 *}$ Wiwin Retnowati, ${ }^{2}$ Rize Budi Amalia \\ Universitas Airlangga; Jalan Airlangga No. 4-6 Surabaya \\ "Corresponding author: wiwinretnowati@gmail.com
}

\begin{abstract}
Abstrak
Tujuan program pengabdian masyarakat ini adalah untuk membekali siswa SMP di kelurahan Bangsalsari kecamatan Bangsalsari kabupaten Jember tentang pengetahuan mengenai kesehatan reproduksi agar remaja putri akan lebih siap untuk menghadapi masa dewasa dan untuk mengurangi frekuensi pernikahan dini. Metode yang dilakukan adalah, penyuluhan reproduksi remaja, pelatihan dan pendampingan kader kesehatan. Hasil kegiatan adalah para remaja telah mampu mempraktekkan pengetahuannya dalam kehidupan sehari-hari untuk menjaga kesehatan reproduksinya dan sebagai pioner pada lingkungan sekitar maupun adik kelas mereka serta telah terbentuknya kader kesehatan reproduksi remaja putri.
\end{abstract}

Kata kunci—kader kesehatan, pioneer siswa, reproduksi remaja.

\section{Abstract}

The purpose of this community service program is to equip Junior High School students in the Bangsalsari village, Bangsalsari sub-district, Jember Regency about knowledge about health, so that young women will be better prepared for the future and to multiply early marriages. The method used is youth counseling, training and health cadre assistance. The result of the activity is that young people who have successfully practiced their knowledge in daily life for reproductive health and as pioneers in the surrounding environment and their junior class have also developed a young female health cadre.

Keywords - health cadres, pioneers of students, adolescent reproduction

\section{PENDAHULUAN}

$\mathrm{P}$ Perkawinan yang dilakukan pada usia remaja disebut perkawinan dini (Romauli \& Vindari, 2012). Pada tahun 2018, Indonesia menduduki peringkat ke-7 di dunia dan ke-2 di ASEAN tentang pernikahan usia dini (Rosalin, 2018). Menurut data DALDUK KB (Pengendalian Penduduk Keluarga Berencana) dan KS DP3AKB (Kekerasan Seksual Dinas Pemberdayaan Perempuan Perlindungan Anak Keluarga Berencana) Kabupaten Jember, bahwa pada tahun 2017 telah terjadi pernikahan dini sebanyak 19.119 pernikahan dan sekitar 29\% merupakan pernikahan di bawah usia 20 tahun (sebanyak 531 pernikahan). Pernikahan dini di kabupaten Jember biasanya disebabkan antara lain: budaya perkawinan usia dini, karena orang tua takut anaknya dikatakan perawan tua sehingga segera dinikahkan, orang tua memilih untuk menjodohkan anak perempuan mereka. Budaya ini dapat memberi dampak negatif karena bisa menyebabkan bertambah banyaknya perkawinan di usia muda. Keadaan ini tentunya tidak lepas dari kondisi yang membentuk pola kehidupan mereka yang diwarisi secara turun-temurun, yang memandang proses kehidupan itu tidak lebih dari sesuatu yang bersifat rutinitas, dan (2) rendahnya tingkat pendidikan serta rendahnya tingkat ekonomi.

Pernikahan yang dilangsungkan pada usia remaja umumnya menimbulkan masalah baik secara fisiologis, psikologis maupun sosial ekonomi. Dampak nyata dari pernikahan usia dini adalah terjadinya abortus atau keguguran karena secara fisiologis organ reproduksi (khususnya rahim) belum sempurna (Romauli \& Vindari, 2012).

Remaja terutama dari lingkungan keluarga prasejahtera sangat rentan melakukan pernikahan usia dini. Beberapa faktor penyebab adalah pemaksaan dari orang tua, pergaulan bebas, rasa 


\section{Retnowati \& Amalia / Jurnal Karinov Vol. 2 No. 3 (2019) 204-207}

keingintahuan tentang dunia seks, faktor ekonomi, faktor lingkungan, dan rendahnya pendidikan, interpretasi agama dan keluarga, serta adat istiadat yang dilakukan keluarga (Maryanti \& Septikasari, 2009; Rosalin, 2018).

Berdasarkan Pasal 9 dan 10 Undang-Undang No. 23 Tahun 2002 tentang Perlindungan Anak, maka semua orang termasuk anak mempunyai hak untuk mendapatkan informasi dan pengetahuan, salah satunya adalah pengetahuan reproduksi. Salah satu bentuk pendidikan kesehatan reproduksi adalah pembekalan informasi dan pengetahuan mengenai pubertas. Pubertas adalah waktu yang menandai peralihan fase anak-anak menjadi dewasa, melalui proses biologis yang berpengaruh pada perkembangan tubuh (Krugu \& Kwaak, 2019).

Perubahan adalah ciri utama dari proses biologis pubertas. Perubahan hormonal secara kualitatif dan kuantitatif terjadi antara masa pre-pubertas dan dewasa. Akibatnya terjadi pertumbuhan yang cepat dari berat badan dan panjang badan, perubahan dalam komposisi tubuh dan jaringan tubuh, dan timbulnya ciri-ciri seks sekunder yang menghasilkan perkembangan "girl into a woman". Pada masa ini, perubahan somatik sangat bervariasi dalam umur saat mulai dan berakhirnya, kecepatan dan sifatnya, namun akan mengikuti urutan yang sama dalam pertumbuhan dan perkembangan somatiknya. Perubahan ini dimulai dengan telarche (perkembangan payudara), pubarche (pertumbuhan rambut pubis), kemudiaan diikuti dengan menarche (menstruasi pertama kali) (Soetjiningsih, dkk., 2008).

Berdasarkan studi pendahuluan yang dilaksanakan pada Bulan Januari 2019, pengetahuan remaja putri terkait pubertas dan kesehatan reproduksi masih rendah serta terdapatnya masalah-masalah kesehatan reproduksi seperti keputihan dan dismenorhea yang tidak ditangani dengan baik.

Pengetahuan tentang pubertas dapat diperoleh melalui lingkungan keluarga dan sekolah. Namun, belum semua orang tua memberikan pemahaman yang baik karena terbatasnya pengetahuan orang tua dan anggapan bahwa hal ini masih tabu untuk dibicarakan. Topik pubertas juga tidak ada dalam kurikulum pendidikan, dan belum optimal diberikan di Unit Kesehatan Sekolah. Hal ini berdampak pada sulitnya akses remaja putri untuk mendapatkan informasi terkait kesehatan reproduksi. Di Indonesia, UNICEF bersama dengan Tim Pembina Usaha Kesehatan Sekolah telah menerbitkan modul kesehatan reproduksi berupa komik Manajemen Kesehatan Menstruasi yang ditujukan pada siswa Sekolah Dasar dan Madrasah Ibtidaiyah yang dipublikasikan sejak 2016, namun semua remaja putri di wilayah binaan di Kecamatan Bangsalsari, belum pernah membaca dan mendapatkan informasi ini saat di Sekolah Dasar dan Madrasah Ibtidaiyah.

Keputihan merupakan masalah yang banyak terjadi dan dianggap lazim pada remaja putri. Remaja perempuan di sekitar masa pubertas adanya discharge vagina atau lebih dikenal dengan istilah keputihan. Discharge yang jernih, tidak gatal atau berbau menunjukkan kemungkinan discharge tersebut adalah leukorea fisiologis akibat stimulasi estrogen dari ovarium terhadap uterus dan vagina. Pemeriksaan mikroskopis leukorean fisiologis menunjukkan beberapa leukosit dan maturasi sel epitel vagina akibat pengaruh estrogen, sedangkan pada pemeriksaan kultur tidak didapatkan kuman patogen. Namun kurangnya higienitas akan berdampak pada terjadinya leukorea yang patologis yang ditandai dengan adanya keputihan yang berbau, gatal dan berwarna kekuningan atau kehijauan. Pencegahan dan penanganan yang baik terhadap keputihan akan meningkatkan status kesehatan reproduksi remaja.

Pengetahuan remaja putri khususnya di SMP Islam Darul Hidayah Kelurahan Gambirono Kecamatan Bangsalsari dan SMP Bany Khozin Kelurahan Karangsono Kecamatan Bangsalsari, terkait pubertas dan kesehatan reproduksi masih rendah serta terdapatnya masalah-masalah kesehatan reproduksi seperti keputihan dan dismenorhea yang tidak ditangani dengan baik, sehingga perlunya sikap yang baik pada reproduksi untuk meningkatkan kualitas kesehatan reproduksi.

Kegiatan pengabdian masyarakat ini bertujuan membentuk Kader Kesehatan Reproduksi Remaja. Dengan adanya kader tersebut, akan terjadi transfer pengetahuan dan berdampak pada peningkatan kesehatan reproduksi remaja putri khususnya di SMP Bangsalsari. Inisiasi pembentukan kader remaja karena komunikasi teman sebaya merupakan salah satu bentuk komunikasi yang efektif dengan tujuan para kader dapat meneruskan infomasi ini pada lingkungan sekitar serta adik kelas mereka nantinya.

\section{METODE}

Kegiatan pengabdian masyarakat ini dilaksanakan bersama-sama antara pengusul dengan mitra. Tahapan kegiatan yang dilaksanakan adalah sebagai berikut:

1. Pembekalan materi substantif yaitu teori dan praktek, yang meliputi: 


\section{Retnowati \& Amalia / Jurnal Karinov Vol. 2 No. 3 (2019) 204-207}

a. Penyuluhan tentang kesehatan reproduksi remaja (organ reproduksi perempuan, pubertas dan menstruasi, IMS).

b. Penyuluhan mengenai pubertas dan kesehatan reproduksi kepada siswi SMP dengan menggunakan media leaflet, power point, kuesioner pre dan post penyuluhan dengan luaran meningkatkan pengetahuan remaja putri.

2. Pelaksanaan Kelompok sasaran, yaitu pelatihan penggunaan lembar balik kesehatan reproduksi remaja bagi para kader.

3. Pembentukan Kader Kesehatan Reproduksi remaja yang terdiri dari lima (5) sampai sepuluh (10) siswa per kelompok.

Pendampingan Kader Kesehatan Reproduksi remaja SMP Islam Darul Hidayah Kelurahan Gambirono Kecamatan Bangsalsari dan SMP Bany Khozin Kelurahan Karangsono Kecamatan Bangsalsari dengan menggunakan media Lembar Balik Kesehatan Reproduksi untuk Remaja

\section{HASIL DAN PEMBAHASAN}

Pelaksanaan Penyuluhan tentang kesehatan reproduksi remaja (organ reproduksi perempuan, pubertas dan menstruasi, IMS) diikuti oleh 138 siswi yang dipilih secara acak dari kedua sekolah yaitu SMP Islam Darul Hidayah Kelurahan Gambirono Kecamatan Bangsalsari dan SMP Bany Khozin Kelurahan Karangsono Kecamatan Bangsalsari Kabupaten Jember.

Kegiatan diawali dengan memberikan soal pretest untuk mengukur pengetahuan siswa tentang kesehatan reproduksi. Setelah pretest diberikan, kegiatan pelatihan dilakukan dengan memberikan materi menggunakan media powerpoint, video, gerak, dan lagu. Media yang dipilih diharapkan dapat membuat siswa lebih mudah memahami dan mengingat materi yang diberikan.

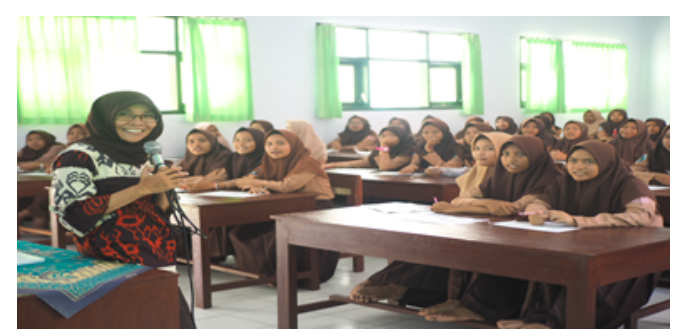

Gambar 1. Pelatihan kader kesehatan reproduksi remaja di SMP Bany Khozin

Selanjutnya, pelatihan penggunaan lembar balik kesehatan reproduksi remaja dan pendampingan bagi para kader. Tim pengabdi juga memberikan panduan kepada duta kesehatan reproduksi tentang cara-cara untuk berbicara didepan kelas dan menyampaikan pesan pada teman agar kader remaja tersebut lebih mudah melaksanakan perannya.

Pentingnya Penyuluhan tentang kesehatan reproduksi remaja, pembentukan kelompok duta kesehatan reproduksi, dan pembagian buku panduan reproduksi remaja khususnya di SMP Islam Darul Hidayah Kelurahan Gambirono Kecamatan Bangsalsari dan SMP Bany Khozin Kelurahan Karangsono Kecamatan Bangsalsari agar dengan informasi yang benar diharapkan remaja memiliki sikap dan tingkah laku yang bertanggung jawab mengenai proses reproduksi. Dalam rangka menumbuh kembangkan perilaku hidup sehat bagi remaja, maka perlu kepedulian dalam bentuk pelayanan dan penyediaan informasi yang benar serta sepahaman bersama akan pentingnya kesehatan reproduksi remaja sehingga dapat membantu mereka dalam menentukan pilihan masa depannya. Program Kesehatan Reproduksi Remaja merupakan topik yang perlu diketahui oleh masyarakat khususnya para remaja agar mereka memiliki informasi yang benar mengenai proses reproduksi serta berbagai faktor yang ada disekitarnya.

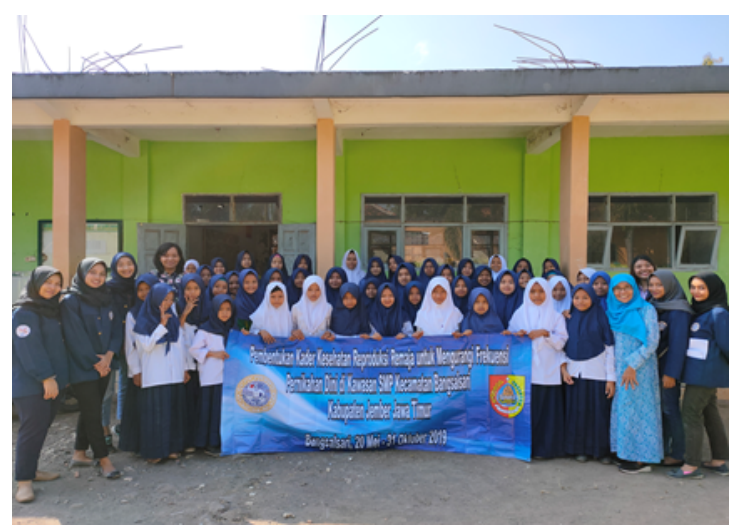

Gambar 2. Kader kesehatan reproduksi remaja di SMP Bany Khozin

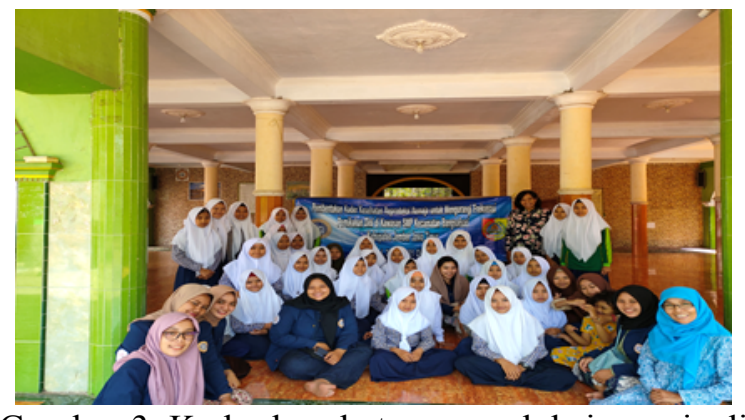

Gambar 3. Kader kesehatan reproduksi remaja di SMP Islam Darul Hidayah 
Retnowati \& Amalia / Jurnal Karinov Vol. 2 No. 3 (2019) 204-207

Pengetahuan yang baik tentang pubertas dapat meningkatkan status kesehatan reproduksi di masa yang akan datang terkait higienitas menstruasi, pemahaman tentang keluhan-keluhan umum selama menstruasi, serta makna dari menstruasi itu sendiri. Pengetahuan tentang pubertas yang kurang akan berpengaruh terhadap ketidaksiapan praktik menstrual hygiene. Selain itu kurangnya informasi mengenai anatomi tubuh, organ reproduksi dan menarke berdampak pada peningkatan insiden hubungan seksual yang berisiko.

Melalui pembentukan kader kesehatan reproduksi remaja diharapkan dapat meningkatkan kualitas sumber daya manusia yang nantinya akan menentukan keberhasilan Indonesia mewujudkan Indonesia Emas pada tahun 2045. Remaja memiliki dua nilai yaitu nilai harapan (idelisme) dan nilai kemampuan. Apabila kedua nilai tersebut tidak terjadi keselarasan maka akan muncul bentuk-bentuk frustasi yang dapat merangsang generasi muda untuk melakukan tindakan-tindakan menyimpang. Dari sudut pandang kesehatan, tindakan menyimpang yang mengkhawatirkan adalah masalah yang berkaitan dengan seks bebas (unprotected sexuality), penyakit menular seksual (PMS), kehamilan di luar nikah atau kehamilan yang tidak dikehendaki (adolecent unwanted pragnancy) di kalangan remaja yang akhirnya dapat menimbulkan masalah-masalah lainnya yaitu aborsi dan pernikahan dini. Semua masalah ini disebut sebagai masalah kesehatan reproduksi remaja yang harus mendapatkan perhatian khusus dari berbagai organisasi secara internasional (Depkes RI, 2008).

\section{SIMPULAN}

Pelatihan kesehatan reproduksi bagi siswa terbukti dapat meningkatkan pengetahuan dan kesadaran siswa tentang tubuh mereka dan kesehatan khususnya kesehatan reproduksi. Selama proses kegiatan beberapa siswa menyampaikan bahwa selama ini malu dan menganggap tidak sopan ketika berbicara tentang kesehatan reproduksi. Hal ini menjadi pemikiran akan pentingnya muatan kesehatan reproduksi dalam kurikulum pembelajaran siswa SMP.

\section{DAFTAR RUJUKAN}

Departemen Kesehatan RI, (2008). Pusat Promosi Kesehatan, Promosi Kesehatan Sekolah, Jakarta.
Krugu, J. K., \& Anke, V. K. (2019). Promoting Adolescent Sexual and Reproductive Health Through Schools in Low Income Countries an Information.

Maryanti, D., \& Septikasari, M. (2009). Buku Ajar Kesehatan Reproduksi Teori dan Praktikum. Yogyakarta. Numed.

Romauli, S., \& Vindari, A. (2012). Kesehatan Reproduksi buat Mahasiswi Kebidanan. Yogyakarta. Nuha Medika.

Soetjiningsih, M. B. Narendra., Sularyo, T.S., Ranuh, G., Suyitno, H., \& Wiradisuria, S. (2008). Buku Ajar: Tumbuh Kembang Anak dan Remaja. Sagung Seto. 